\section{КОРРЕКЦИЯ НАРУШЕНИЙ} У ПРОФЕССИОНАИЬНЫХ СПОРТСМЕНОВ
СТОМАТОЛОГИЧЕСКОГО СТАТУСА

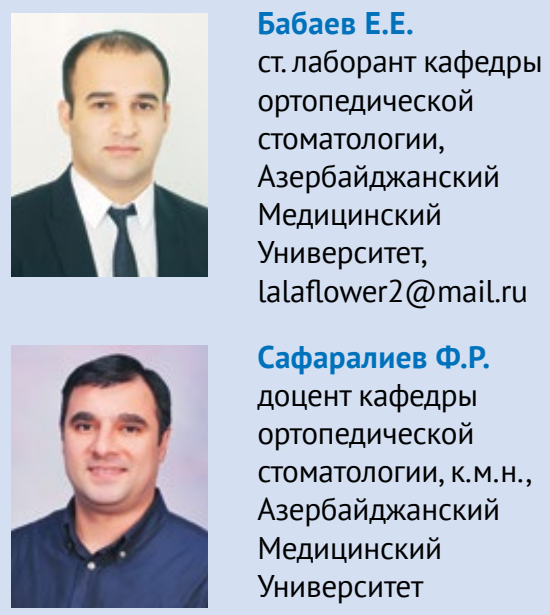

Систематические физические упражнения и спортивные тренировки, которые, как известно, имеют огромное значение для укрепления здоровья и повышения сопротивляемости организма, при определенных условиях также могут оказаться причиной развития перенапряжения, а в некоторых случаях и патологических процессов в различных органах и системах организма [3]. При этом одним из важных этиопатогенетических факторов, способствующих снижению иммунологической реактивности организма профессиональных спортсменов и частым нарушениям в центральной нервной и эндокринной системах, являются чрезмерные физические нагрузки или так называемый синдром перетренированности $[9,10,11]$. Согласно результатам немногочисленных научных исследований, проводимых в этой области, вышеуказанные нарушения зачастую приводят к развитию, широкой распространенности и повышению интенсивности заболеваний полости рта. При этом сравнительный анализ клинико-эпидемиологических данных, полученных при обследовании спортсменов и их сверстников, не занимающихся спортом, выявил у первых высокие показатели по частоте встречаемости кариеса зубов, травм и аномалий челюстно-лицевой области и воспалительных заболеваний тканей пародонта $[8,16,17,19]$. Необходимо особо отметить тот факт, что спортивный иммунодефицит, развивающийся в период интенсивных физических нагрузок и характеризующийся микроэлементным дисбалансом, негативными изменениями в кислотно-щелочном равновесии и микробиоценозе полости рта, очень часто приводит к хронизации одонтогенных очагов инфекции, которые при благоприятных условиях в качестве этиопатогенетического разрешающего фактора могут оказывать существенное отрицательное воздействие на орга-

\section{Резюме}

Резкое снижение иммунологической реактивности различных органов и систем организма профессиональных спортсменов на фоне интенсивных физических нагрузок приводит к повышению уровня распространенности и интенсивности воспалительных заболеваний тканей пародонта. Согласно показателям индекса выраженные патологические процессы в околозубных тканях относительно часто обнаруживаются у обследуемых уже в младших возрастных группах. Применение в лечебно-профилактических целях биологически нейтральных медикаментозных средств растительного и животного происхождения сопровождалось на фоне перетренированности существенными позитивными изменениями в клинических и лабораторных проявлениях воспалительных заболеваний пародонта. Статистический анализ полученных результатов показал значимое снижение показателей по гигиеническому и пародонтальному индексам и количественному содержанию в смешанной слюне секреторного иммуноглобулина, причем данная тенденция прослеживалась на всех этапах исследований и почти во всех группах профессиональных спортсменов.

Ключевые слова: заболевания пародонта у спортсменов, физические нагрузки, гигиенический индекс, пародонтальный индекс, секреторный иммуноглобулин А. 
CORRECTION OF VIOLATIONS OF THE DENTAL STATUS AMONG PROFESSIONAL ATHLETES

Babaev E.E., Safaraliev F.R.

\section{The summary}

Marked reduction of the immunological reactivity of various organs and systems of professional athletes on the background of intense physical activities leads to an increase in the prevalence and intensity of inflammatory diseases of the periodontal tissues. According to the index indicant expressed pathological processes in periodontal tissues frequently found already in the examined younger age groups. Use in therapeutic and prophylactic purposes biologically neutral medication of plant and animal origin during overtraining syndrome accompanied by significant positive changes in the clinical and laboratory manifestations of inflammatory periodontal disease. Statistical analysis of the results showed a significant decrease in data of hygiene and periodontal indices, and quantitative content secretor immunoglobulin in the mixed saliva, and this trend could be observed at all stages of research and almost in all groups of professional athletes.

Keywords: periodontal disease in athletes, exercise, hygiene index, periodontal index, secretory immunoglobulin A.

низм спортсмена в целом [1]. Своевременное выявление, рациональная профилактика и устранение подобных факторов риска, оказывающих самое непосредственное и негативное влияние на спортивную работоспособность и результативность, является одной из актуальных задач современной стоматологии.

\section{Цель работы}

Совершенствование методов профилактики и лечения воспалительных заболеваний пародонта у профессиональных спортсменов.

\section{Материалы и методы исследований}

Оценка стоматологического статуса 475 профессиональных спортсменов-единоборцев (борьба, бокс, кикбоксинг) проводилась с использованием методик и критериев, предложенных ВО3, индекса нуждаемости в лечении заболеваний пародонта, CPITN, 1980. Стоматологический осмотр проводили с помощью специального набора диа- гностических инструментов: стоматологического зеркала, пародонтального зонда и пинцета. В зависимости от применяемых лечебно-профилактических средств, выбранной методики и сравнительной оценки их эффективности 55 больных с заболеваниями тканей пародонта легкой степени тяжести были разделены на 4 группы.

Первая группа 14 больных - применение экстракта на основе цветков шафрана посевного (Crocus Sativus L.) [5,7]; во второй группе 14 больных использовали аппликации гели «Апибальзам 1» (состав: прополис, растительное масло); третью группу составили 14 пациентов, которым назначались орошения десны препаратом «Бальзам гранатовый» (состав: прополис, экстракты маральего корня, золотого корня, аралии маньчжурской, пихтовой хвои и т.д.) после чистки зубов, в течение дней; в четвертой группе 13 профессиональных спортсменов с пародонтопатиями использовали препарат «Solident» на растительной основе (состав: гранатовая кожура, шалфей, зеленый чай) [15]. Вышеуказанные медикаментозные средства применялись в течение 10 дней. Контрольные стоматологические осмотры проводили на различных этапах исследований (непосредственно после лечения; через 1 месяц; через 3 месяца). Клиническое обследование включало: индекс эффективности гигиены полости рта (РНР) (Podshadley A.G., Ha1 еy P., 1968); упрощенный индекс кровоточивости десневой борозды SBI (Muhlemann H.R., Son, 1971). Состояние местного иммунитета оценивали по содержанию секреторного иммуноглобулина S-IgA в ротовой жидкости пациента до и после лечения. Исследованию подвергалась нестимулированная смешанная слюна. Уровень иммуноглобулинов определяли с помощью метода радиальной иммунодиффузии (Manchini G. et al., 1965). Статистические методы исследования включали методы вариационной статистики (определение средней арифметической величины - M, их средней стандартной ошибки - $\mathrm{m}$, критерия значимости Стьюдента - t). Статистическая обработка результатов клинических исследований выполнялась с использованием стандартных программных пакетов прикладного статистического анализа (Microsoft Excel и Statistica 6.0 для Windows).

\section{Результаты собственных исследований}

Первичный клинический осмотр полости рта профессиональных спортсменов зафиксировал клинические проявления патологических процессов в тканях десны и незначительное повышение показателей индекса CPITN. Полученные данные отражали разную степень патологиче- 
ских изменений воспалительно-деструктивного характера в тканях пародонта при обследовании профессиональных спортсменов, относящихся к различным возрастным группам. На фоне высокоинтенсивных нагрузок высокие показатели по частоте обнаружения секстантов с кровоточивостью выявлялись в группе профессиональных спортсменов юношеского и подросткового возрастных периодов. Причем необходимо отметить меньшие в сравнительном аспекте показатели по исследуемому фактору при стоматологическом обследовании в аналогичных возрастных группах практически здоровых лиц, не занимающихся какими-либо видами спорта регулярно. Итак, на основании проведенных ранее исследований можно заключить, что воспалительные заболевания тканей пародонта у профессиональных спортсменов сопровождаются более выраженными клиническими проявлениями, чем у не спортсменов, и частота их растет с ростом интенсивности физических нагрузок, которые, как известно, негативно влияют на функциональное состояние организма, вызывая определенные нарушения в различных органах. В связи с увеличением возраста и частого выявления у более взрослых спортсменов синдрома перетренированности в старших возрастных группах резко снижается частота встречаемости секстантов с интактным пародонтом и с кровоточивостью, который является наиболее частым клиническим проявлением заболеваний пародонта легкой степени тяжести (рис. 1). Сравнительно низкий уровень гигиены полости рта и более выраженные патологические изменения в околозубных тканях, характеризующиеся наличием значительного количества секстантов с зубным налетом и с зубными камнями, наблюдался среди профессиональных спортсменов, возраст которых составлял 32 года и старше $(1,7 \pm 0,09)$.

Воспалительные заболевания пародонта самой тяжелой степени регистрировались при обследовании полости рта у высококвалифицированных спортсменов самой старшей возрастной группы. Здесь был установлен высокий уровень частоты встречаемости патологических пародонтальных карманов, которые представляют сбой признаки развития тяжелых деструктивных процессов в тканях пародонта и которые при отсутствии своевременной и качественной терапии приводят к потере зубов. Секстанты с патологическими карманами глубиной 4-5 мм диагностировались у $37,1 \pm 4,08 \%$ профессиональных спортсменов в возрасте 32 года и старше (число секстантов $2,3 \pm 0,10)$, а количество спортсменов в средней возрастной группе с исследуемой патологией

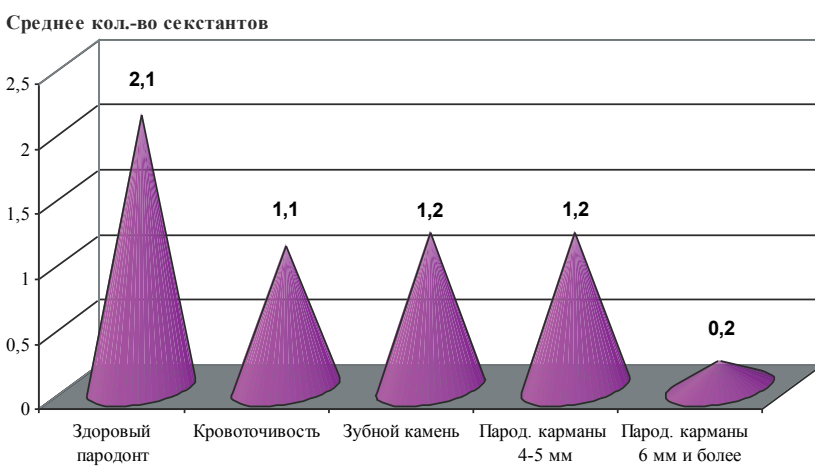

Рис. 1. Состояние пародонта у спортсменов возрастной группы старше 32 лет

составило всего $14,1 \pm 2,35 \%$ (число секстантов $1,0 \pm 0,07)$. У профессиональных спортсменов старшего возраста со сравнительно, по нашему мнению, более частым, чем у молодых спортсменов, развитием синдрома перетренированности высокий уровень и тяжелая степень выраженности и клинической симптоматики основных стоматологических заболеваний, в частности, существенное ухудшение состояния тканей пародонта, связано со снижением функциональной активности факторов местной неспецифической иммунной защиты, но при этом необходимо отметить и нельзя исключать патогенетической роли неудовлетворительной гигиены полости рта и отсутствия своевременной и квалифицированной стоматологической помощи.

Таким образом, оценка возрастной структуры индекса CPITN свидетельствовала о высоком уровне распространенности и интенсивности воспалительных заболеваний пародонта во всех обследуемых возрастных группах профессиональных спортсменов. Изучение данного фактора позволяет, что очень важно, определить потребность в специализированной пародонтологической помощи с учетом тяжести течения заболеваний, возникающих и развивающихся у обследуемых на фоне интенсивных тренировок и эмоционального стресса и этиологических факторов возникновения и развития пародонтопатий. При качественной оценке рассматриваемого показателя установлено, что плохая гигиена чаще всего была отмечена в контрольной группе у спортсменов. Неудовлетворительная гигиена полости рта, наблюдавшаяся практически во всех группах, но в большей степени в первой и второй группах, явилась результатом наличия среди спортсменов-единоборцев определенного числа лиц, нуждавшихся в гигиеническом обучении (табл. 1). Наличие более частых случаев выявления секстантов с кровоточивостью и зубными камнями, по сравнению с показателями по частоте встречаемости здоровых секстантов, 
свидетельствует о высоком уровне нуждаемости обследуемых, особенно в старшей возрастной группе, в пародонтологическом лечении. Именно в этой группе спортсменов потребность в данном виде стоматологической помощи определялась в больших, по сравнению с другими группами, значениях и составила 90,0 $2,54 \%$.

Синдром перетренированности, развивающийся на фоне снижения защитных сил организма в результате интенсивных физических нагрузок, приводит к увеличению частоты встречаемости воспалительных заболеваний пародонта и их обострений у профессиональных спортсменов, возраст которых еще не достиг 23 лет.

Так, значения исследуемого индекса с позиций лиц, нуждающихся в удалении зубного камня,

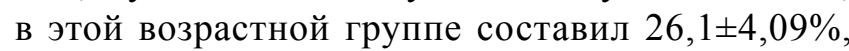
более высокий процент по данному фактору определялся при клиническом исследовании состояния тканей пародонта у спортсменов старшего возраста. Показатели нуждаемости в осуществлении профессиональной гигиены полости рта, в частности в удалении над- и поддесневых зубных отложений, в возрастной группе 24-32 года по сравнению с предыдущей группой обследуемых возросли почти в два раза и составили 43,6 $\pm 3,34 \%$. Схожая тенденция в повышении значений индекса CPITN наблюдалась и в третьей группе профессиональных спортсменов. Структурные и функциональные нарушения в органах и тканях полости рта, как и во всем организме спортсменов под действием чрезмерных интенсивных физических и психоэмоциональных нагрузок, особенно в соревновательный период, приводят к обострению патологических процессов и развитию тяжелых форм воспалительных заболеваний пародонта, что обуславливает высокий уровень нуждаемости обследуемых спортсменов-единоборцев в комплексном лечении, включающим как консервативную терапию, так и хирургические методы лечения. Статистический анализ результатов клинических исследований выявил максимальные значения по вышеуказанному фактору в возрастной

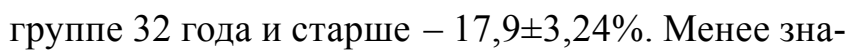
чимые показатели по выраженности тяжелых форм пародонтопатий и потребности в их лечении были обнаружены у профессиональных спортсменов подросткового и среднего возрастов.

На основании данных экспертного анализа результатов клинико-эпидемиологических исследований была осуществлена попытка повышения эффективности профилактики и лечения воспалительных заболеваний пародонта и снижения уровня рецидивов и побочных действий при применении некоторых медикаментозных средств, развитие которых вполне допустимо на фоне синдрома перетренированности у профессиональных спортсменов-единоборцев. Именно с этой целью особое внимание научно-исследовательской группы было обращено к улучшению стоматологического статуса с применением в комплексном лечении биологически нейтральных препаратов.

После окончания курса лечения отсутствовали жалобы и отмечалась нормализация клинических параметров, таких как воспаление и кровоточивость. На начальных этапах после завершения аппликаций биологически нейтральных лекарственных через значения индекса кровоточивости SBI значительно снизились во всех обследуемых группах спортсменов, в полости рта которых выявлялись пародонтопатии легкой степени тяжести. При изучении динамики изменения показателей по исследуемому индексу на последующих этапах клинических исследований определилась ярко выраженная тенденция в снижении показателей SBI через 3 месяца в первой и третьей группах обследованных по сравнению с данными, полученными сразу после завершения базовой терапии (рис. 2). Так, в первой группе значения индекса SBI в указанные сроки составили: $18,0 \pm 0,90 \%$ и $13,7 \pm 0,82 \%$ соответственно.

Клинически наблюдалось улучшение состояния тканей пародонта во второй и четвертой группах, что подтверждалось данными, зарегистрированными до лечения и на определенных этапах исследований. На основании статистического анализа

Таблийа 1

Нуждаемость обследованных в пародонтологической помощи (индекс CPITN)

\begin{tabular}{|c|c|c|c|c|c|}
\hline \multirow[b]{2}{*}{ Возрастные группы } & \multirow[b]{2}{*}{ Кол-во обследованных } & \multirow{2}{*}{$\begin{array}{c}\text { Потребность } \\
\text { в гигиеническом } \\
\text { обучении }\end{array}$} & \multirow{2}{*}{$\begin{array}{c}\text { Число нуждаюшихся } \\
\text { в пародонтологической } \\
\text { помощи }\end{array}$} & \multicolumn{2}{|c|}{ В том числе } \\
\hline & & & & $\begin{array}{c}\text { Удаление зубного } \\
\text { камня }\end{array}$ & Комплексное лечение \\
\hline До 23 лет & 115 & $20,9 \pm 3,79$ & $26,1 \pm 4,09$ & $26,1 \pm 4,09$ & - \\
\hline 24-32 лет & 220 & $34,6 \pm 3,21$ & $49,1 \pm 3,37$ & $43,6 \pm 3,34$ & $5,5 \pm 1,53$ \\
\hline 32 г. и стар. & 140 & $3,6 \pm 1,57$ & $90,0 \pm 2,54$ & $72,1 \pm 3,79$ & $17,9 \pm 3,24$ \\
\hline Всего & 475 & $22,1 \pm 1,90$ & $55,6 \pm 2,28$ & $47,8 \pm 2,29$ & $7,8 \pm 1,23$ \\
\hline
\end{tabular}




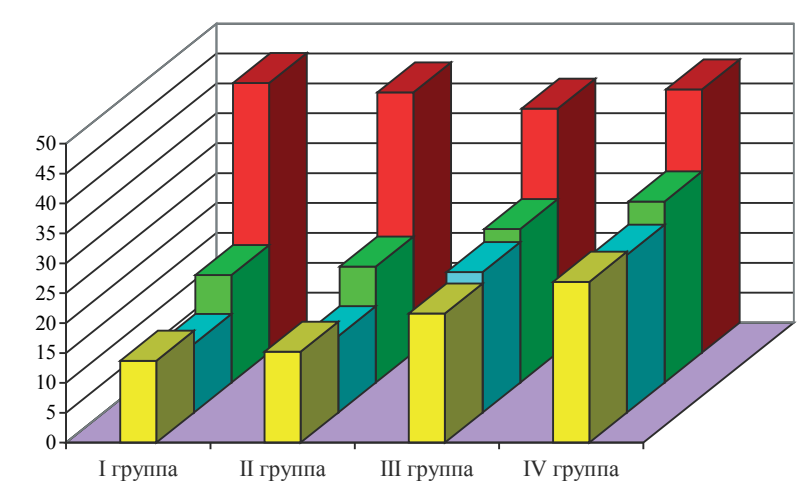

口До лечения

$\square$ После лечения

$\square$ Через 1 мес.

$\square$ Через 3 мес.

Рис. 2. Динамика показателей индекса кровоточивости десневой борозды (индекс SBI) в различных группах спортсменов

полученных по этим группам результатов можно сделать заключение об эффективности применения в терапии воспалительных заболеваний околозубных тканей препаратов на основе прополиса и комбинированного растительного средства «Солидент». Индекс кровоточивости десневой борозды значимо снизился в показателях в процессе применения аппликаций данными препаратами, при этом важно отметить профилактическую эффективность вышеуказанных средств, что подтверждается результатами наблюдений на завершающем этапе исследований. Значения индекса SBI на 3-й месяц наблюдений в исследуемой группе составили $26,9 \pm 0,79 \%$ против $44,0 \pm 0,65 \%$ после лечения.

Анализ динамики результатов клинических исследований по всем группам больных, где в программу профилактики и лечения воспалительных заболеваний пародонта был включен ряд нейтральных препаратов, обладающих в своем составе целым спектром биологически активных микро- и макроэлементов, позволил установить выраженное улучшение гигиенического состояния полости рта на всех этапах наблюдений. Оценка эффективности гигиены (по индексу РНР) при первичном стоматологическом осмотре до лечения характеризует уровень гигиены полости рта у обследуемых профессиональных спортсменов как неудовлетворительный (рис. 3). Но уже непосредственно после окончания курса терапии наблюдалось выраженное снижение значений вышеуказанного индекса в первой и второй

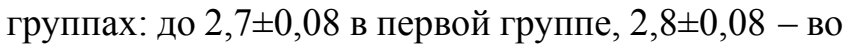
второй; после $1,6 \pm 0,02$ и 1,7 $\pm 0,02$ соответственно $(\mathrm{p}<0,001)$.

Сравнительно менее значимые результаты по гигиеническому состоянию полости рта в динамике наблюдений были зафиксированы после

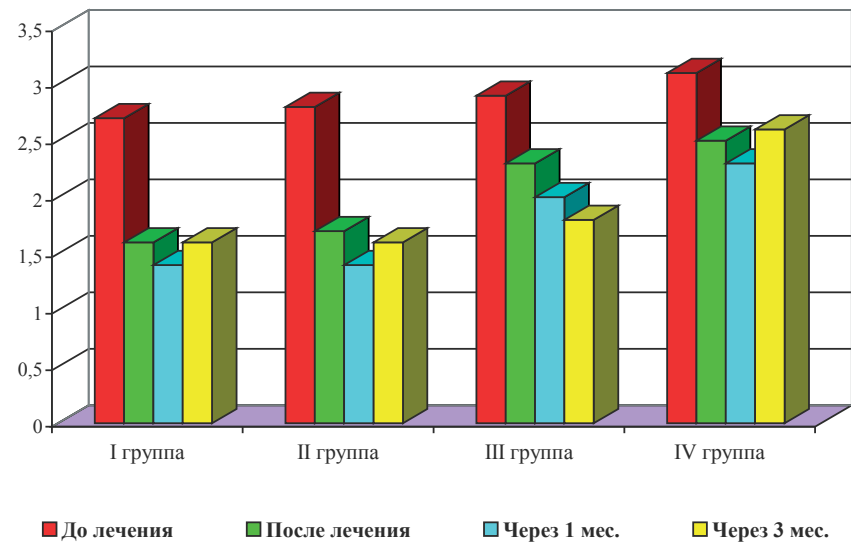

Рис. 3. Оценка эффективности гигиены полости рта (индекс PHP) в разных группах спортсменов

применения гранатового бальзама и комплексного растительного препарата «Солидент» в третьей и четвертой группах больных, где показатели индекса РНР варьировали в пределах от 2,3 40,03 до $2,5 \pm 0,03$ соответственно $(\mathrm{p}<0,05)$.

Удовлетворительная гигиена полости рта и положительная тенденция в полученных индексных данных продолжали наблюдаться в первых двух группах профессиональных спортсменов. Причем данный факт выявлялся на всех последующих, в том числе на завершающем, этапах клинических исследований.

К концу исследований индекс эффективности гигиены РНР продолжал оставаться на более низком по сравнению с результатами до лечения уровне в третьей группе, где больным назначались аппликации гранатового бальзама $-1,8 \pm 0,02$, значение исследуемого индекса через три месяца после начала лечебно-профилактических мероприятий $(\mathrm{p}<0,001)$.

Развитию новых и обострению хронических форм воспалительных заболеваний полости рта у спортсменов с синдромом перетренированности сопутствует выраженное снижение барьерных свойств слюны, слизистой оболочки и околозубных тканей. На фоне этого происходят нарушения кислотно-щелочного баланса и, как результат, повышение кислотности, а также определенный дисбаланс в показателях факторов местного иммунитета, что говорит об ухудшении на фоне ухудшения функционального состояния организма спортсменов в период интенсивного тренировочного процесса. Так, при статистическом анализе результатов биохимических исследований в полости рта состояния местной иммунной системы у профессиональных спортсменов, находящихся в состоянии повышенного физического и эмоциональ- 
ного стресса, особенно в предсоревновательный и соревновательный периоды, установлен достаточно высокий уровень секреторного иммуноглобулина в смешанной слюне что, по нашему мнению, свидетельствует о компенсаторном функционировании и провоспалительной реорганизации местной системы защиты в условиях спортивного режима (табл. 2).

\section{Таблица 2}

Изменение показателей S-IgA у спортсменов различных групп

\begin{tabular}{|c|c|c|c|}
\hline $\begin{array}{c}\text { Группы } \\
\text { обледованных }\end{array}$ & До лечения & После лечения & Через 60 дней \\
\hline $\begin{array}{c}\text { Группа 1 } \\
(\mathrm{n}=14)\end{array}$ & $0,41 \pm 0,003$ & $0,30 \pm 0,002^{*}$ & $0,28 \pm 0,005^{*}$ \\
\hline $\begin{array}{c}\text { Группа 2 } \\
(\mathrm{n}=14)\end{array}$ & $0,44 \pm 0,002$ & $0,28 \pm 0,002^{*}$ & $0,30 \pm 0,002^{*}$ \\
\hline $\begin{array}{c}\text { Группа 3 } \\
(\mathrm{n}=14)\end{array}$ & $0,45 \pm 0,003$ & $0,39 \pm 0,003^{*}$ & $0,37 \pm 0,003^{*}$ \\
\hline $\begin{array}{c}\text { Группа 4 } \\
(\mathrm{n}=13)\end{array}$ & $0,40 \pm 0,004$ & $0,33 \pm 0,003^{*}$ & $0,27 \pm 0,002^{*}$ \\
\hline
\end{tabular}

Примечание: *-различие значений относительно до лечения статистически достоверно $(p<0,001)$.

В ходе лечебно-профилактических мероприятий с применением аппликаций комбинированных биологически нейтральных препаратов в период интенсивных тренировок и высоких нагрузок была выявлена нормализация клинической симптоматики и практически всех показателей неспецифической иммунной защиты полости рта.

Так, при определении количественных показателей секреторного иммуноглобулина в ротовой жидкости установлено более выраженное и достоверное снижение его уровня как на начальных, так и в более поздние сроки исследований в первой и во второй группах обследуемых. Непосредственно сразу после завершения курса терапии с применением экстракта из цветков шафрана посевного и апигеля наблюдались практически равное снижение концентрации IgA в смешанной слюне спортсменов: уровня всех определяемых иммуноглобулинов в слюне (до лечения $0,41 \pm 0,003-0,44 \pm 0,002$ и $0,30 \pm 0,002-0,28 \pm 0,002$ после лечения в первой и второй группах соответственно) $(\mathrm{p}<0,001)$. В остальных группах, по сравнению с двумя предыдущими, наблюдалась менее выраженная иммунокоригирующая эффективность применяемых у данного контингента больных лекарственных средств. Вышеизложенные факты и выявленная тенденция не претерпели значимых изменений и на более отдаленных этапах наблю- дений в группе профессиональных спортсменов, где с целью коррекции иммунологической реактивности органов и тканей полости рта назначались аппликации экстракта на основе цветка шафрана и «Апибальзама».

Наличие сопутствующего или фонового патологического состояния синдрома перетренированности у профессиональных спортсменов-единоборцев обусловливает: высокий уровень частоты встречаемости основных стоматологических заболеваний очень часто неблагоприятный исход лечебных мероприятий; утяжеление течения воспалительных процессов в тканях пародонта и возникновение их рецидивов.

При оценке эффективности применяемых натуральных лекарственных средств, имеющих в своем составе биологически активные компоненты и применяющихся в различных областях медицины, было установлено их противовоспалительное и имунокорригирующее действие. Так, нормализация клинической симптоматики пародонтопатий и показателей неспецифической иммунной защиты ротовой полости спортсменов наблюдалась при применении комплексного растительного препарата «Solident» и «Бальзам гранатовый», обладающих антибактериальным и прооксидантным действием $[2,6,12]$. Более выраженная положительная динамика в структурной и функциональной реорганизации факторов иммунологической реактивности, нарушения в которой нередко возникали и возникают на фоне синдрома перетренированности, наблюдалась при применении в полости рта профессиональных спортсменов экстракта шафрана посевного (Crocus Sativus L.) и препарата на основе прополиса и растительного масла «Апибальзам 1». Применение вышеуказанных средств в лечении воспалительных заболеваний пародонта было обусловлено наличием в их составе биоантиоксидантов и выявленной в результате многочисленных научных исследований эффективностью применения данных препаратов в лечении некоторых соматических и стоматологических заболеваний $[4,13,14,18]$.

\section{Заключение}

Клинико-эпидемиологические и лабораторные исследования стоматологического статуса профессиональных спортсменов выявили степень воздействия интенсивных физических и психоэмоциональных нагрузок и факторов риска возникновения и развития патологических процессов в мягких и твердых тканях пародонта. Организация диспансерного учета и динамического наблюдения за состоянием органов и тканей полости рта у спортсменов на всех этапах тренировочного и подго- 
товительного процессов позволит своевременно диагностировать и эффективно лечить заболевания полости рта уже на начальных этапах, предотвращая таким образом развитие более тяжелых форм патологий и их осложнений и добиваясь улучшения стоматологического статуса, что непременно положительно скажется на качестве жизни профессиональных спортсменов и достижении ими высоких результатов.

\section{ЛИТЕРАТУРА}

1. Антонова И.Н., Розанов Н.Н., Софронов Б.Н., Косицкая Л.С. Хронический стресс у спортсменов, заболевания пародонта и перестройка в иммунной системе// Медицинская иммунология. - 2007. - Т. 9. - №№ 2-3. - С. 294-295.

2. Браславский В.Б, Куркин В.А. Стандартизация сырья и препаратов тополя и прополиса. Фармация. - 2009. - №4. - С. 53-56.

3. Гаврилова Е.А., Чурганов О.А., Иванова О.И. Спортивные стрессорные иммунодефициты // Аллергология и иммунология. - 2002. - №2. - С. 264-267.

4. Дубцова Е.А. Состав, биологические свойства меда, пыльцы и маточного молочка и возможность их применения в лечебном питании. Экспериментальная и клиническая гастроэнтерология, 2009. - №3. - С. 36-43.

5. Мамедов Ф.Ю. Распространенность заболеваний пародонта в очагах эндемии зоба Азербайджанской Республики и особенности лечебно-профилактических мероприятий. Автореф. дис. к.м.н. Баку, 2008. - 20 с.

6. Омаров Ш.М., Орлов Б.Н., Магомедова 3.Ш., Омарова 3.М. / Апитерапия и здоровье человека. Махачкала, 2006. - 535 с.

7. Расулова С. М. Рост и морфогенез шафрана в условиях Апшерона / Материалы VIII Международного симпозиума «Новые и нетрадиционные растения и перспективы их использования» ВНИИ селекции и семеноводства овощных культур. Москва, 2009. - Т. 3. - С. 229-230.

8. Розанов Н.Н. Особенности воспалительных заболеваний пародонта у представителей разных видов спорта // Пародонтология. - 2009. - №4 (53). - С. 42-45.

9. Футорный С.М. Иммунологическая реактивность спортсменок как одно из направлений современной спортивной медицины // Теория и практика физической культуры. 2004. - №1. - C. 16-19.

10. Gani F., Passalacqua G., Senna G., Mosca Frezet M. Sport, immune system and respiratory infections // Allerg. Immunol. (Paris) - 2003. - Vol. 35. - №2. - P. 41-46.

11. Gleeson M. Special feature for the Olympics: effects of exercise on the immune system. Overview: exercise immunology // Immunol. Cell. Biol. - 2000. - Vol.78. - №5. - P. 483-484.

12. Hegazi A. Egyptian propolis: 1-antimicrobial activity and chemical composition of Upper Egypt propolis. / A.Hegazi, F.Hady // Z. Natur-forsch. 2001. - №56 (1-2). - P. 82-88.

13. Kandeler R., Ullrich W.R. Symbolism of plants: examples from European-Mediterranean culture presented with biology and history of art // Journal of Experimental Botany, 2009. - Vol. 60. - №1. - P. 6-8.

14. Kumar R., Singh V., Devi K. [et al.] State of Art of Saffron (Crocus sativus L.) / Agronomy: A Comprehensive Review 2009; Vol.25. - №1. - P. 44-85.

15. Mamedov F.Y., Alkisiyev K.S., Jafarli I.E. «Positive effect of plant preparations on the mucous membrane pathologies at the time of blood diseases» Abstracts of XIII international Eurasian congress of surgery and gastroenteroligy. Baku, 2013. - P. 12-15.

16. Muller-Bolla M., Lupi-Pegurier L., Bolla M., Pedeutour P. Orofacial trauma and rugby in France: epidemiological survey // Dent. Traumatol. - 2003. - Vol.19. - №4. - P. 83-92.

17. Reid B.C., Chenette R., Macek M.D. Prevalence and predictors of untreated caries and oral pain among Special Olympic athletes // Spec. Care. Dentist. - 2003. - Vol.23. - №4. - P. 139-42.

18. Sepaskhah A. R., Yarami N. I. Evaluation of macroscopic water extraction model for salinity and water stress in saffron yield production / International Journal of Plant Production, 2010. Vol.4. - №3. - P. 175-186.

19. Studen-Pavlovich D., Bonci L., Etzel K.R. Dental implications of nutritional factors in young athletes // Dent. Clin. North. Am. - 2000. - Vol.44. - №1. - P. 161-178.

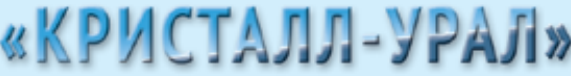

IPOAАस Www.kristallural.ru СТОМАТОАОГИЧЕСКИХ КРИСТАМУРАА МАТЕРИААОВ И ИНСТРУМЕНТОВ

Ждем Вас познакомиться с нашим ассортиментом

г. Екатеринбург, ул. 8 Марта, 80

Тел.: (343) 213-52-04, факс: 257-31-12, 14

E-mail: cristall@k66.ru

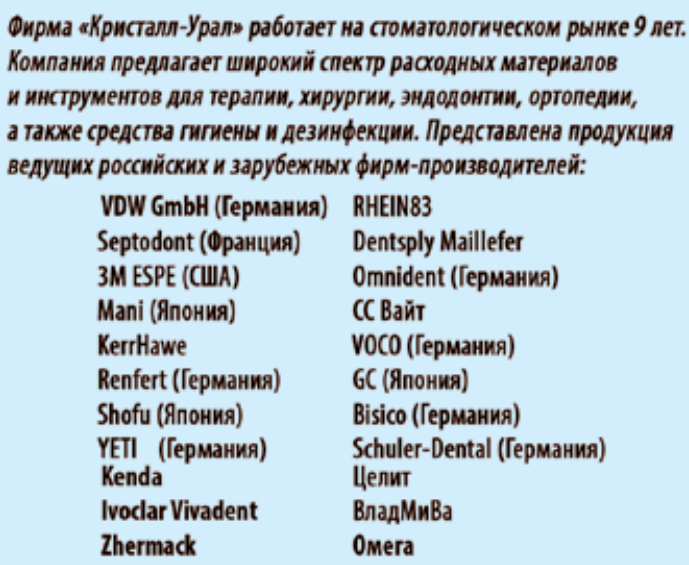

Ждем Ваших заявок по тел.: (343) 213-52-04 E-mail: cristall@k66.ru

Работаем с клиниками из других городов Большой ассортимент! 